\title{
Subway-related trauma at a level 1 trauma centre in Toronto, Ontario
}

\author{
Jordan Ho, MD \\ Muhammad Mansour, MD \\ David Gomez, MD PhD
}

Accepted Nov. 30, 2020

\section{Correspondence to: \\ D. Gomez \\ Donnelly Wing, Room 3-071 \\ St. Michael's Hospital \\ 30 Bond St \\ Toronto ON M5B 1W8 \\ david.gomez@unityhealth.to}

Cite as: Can J Surg 2021 November 2; 64(6). doi: 10.1503/cjs.020219

\begin{abstract}
Background: Given the rising prevalence of subways in combination with an increasing incidence of subway-related injuries, understanding subway-related trauma is becoming ever more relevant. The aim of this study was to characterize the potential causes, injury characteristics and outcomes of subway-related trauma at a level 1 adult trauma centre in Toronto, Ontario.
\end{abstract}

Methods: We conducted a retrospective cohort study to identify patients who presented to the emergency department a level 1 adult trauma centre with a subwayrelated injury between Jan. 1, 2010, and Dec. 31, 2018. Patients were identified via International Statistical Classification of Diseases and Related Health Problems, 10th Revision E-codes (X81, Y02, V050, V051 and W17). We then further screened for descriptions of subway-related injuries. Patients whose injuries did not involve a moving subway train were excluded.

Results: We identified 51 patients who presented to the emergency department after being hit by a moving subway train. The majority of incidents (39 [76\%]) were due to self-harm, $10(20 \%)$ were unintentional injuries, and $2(4 \%)$ were due to assault. The presence of alcohol was detected in 8 patients $(80 \%)$ with unintentional injuries and 3 (8\%) of those with self-inflicted injuries. Thirteen patients $(25 \%)$ had a systolic blood pressure less than $90 \mathrm{~mm} \mathrm{Hg}$. The median Injury Severity Score was 17 (interquartile range 9-29). Seventeen patients (33\%) presented with severe injuries (Abbreviated Injury Scale score $\geq 3)$ in 1 body region, and 19 (37\%) had severe injuries in 2 or more body regions. The most common isolated severe injury was in the lower extremity, and the most common combinations of severe injuries were in the head and lower extremity, and head and thorax. Ten patients (20\%) were declared dead in the emergency department. Of the 41 patients who survived their initial presentation, 12 (29\%) went directly to the operating room, and 17 (41\%) were transferred to the intensive care unit. The overall mortality rate was $29 \%$.

Conclusion: Patients with subway-related injuries experienced high mortality rates and severe injuries. Most incidents were due to self-harm or alcohol-related. Further research into early identification of those at risk and optimal prevention strategies is necessary to curb further incidents.

Contexte : Compte tenu de la fréquentation croissante du métro et de l'incidence à la hausse des accidents qui s'y produisent, il devient de plus en plus important de comprendre les traumatismes qu'ils occasionnent. Le but de cette étude était de caractériser les causes de ces accidents, les particularités des blessures infligées et l'issue des traumatismes traités dans un centre de traumatologie de niveau 1 à Toronto, en Ontario.

Méthodes : Nous avons procédé à une étude de cohorte rétrospective pour identifier les patients amenés aux urgences d'un centre de traumatologie de niveau 1 pour une blessure impliquant le métro entre le $1^{\text {er }}$ janvier 2010 et le 31 décembre 2018. Les patients ont été identifiés au moyen des codes électroniques X81, Y02, V050, V051 et W17 de la $10^{\mathrm{e}}$ révision de la Classification statistique internationale des maladies et des problèmes de santé connexes. Nous avons ensuite recherché la description des blessures impliquant le métro. Les patients dont les blessures n'impliquaient pas un wagon de métro en mouvement ont été exclus.

Résultats : Nous avons recensé 51 patients qui ont été amenés aux urgences après avoir été heurtés par un wagon de métro en mouvement. La majorité des incidents (39 [76\%]) étaient auto-infligés, 10 (20\%) étaient des blessures involontaires et 2 (4\%) étaient dus à une agression. La présence d'alcool a été détectée chez 8 patients $(80 \%)$ victimes de blessures involontaires et chez 3 (8\%) des victimes de blessures auto-infligées. Treize patients $(25 \%)$ avaient une tension artérielle systolique inférieure à $90 \mathrm{mmHg}$. Le score médian de gravité des blessures était de 17 (intervalle 
interquartile 9-29). Dix-sept patients (33\%) présentaient des blessures graves (score à l'échelle abrégée des blessures $\geq 3)$ à une région du corps et $19(37 \%)$ présentaient des blessures graves à 2 régions du corps ou plus. La blessure grave la plus souvent isolée concernait les membres inférieurs et les combinaisons les plus fréquentes de blessures graves concernaient la tête et les membres inférieurs et la tête et le thorax. Le décès de 10 patients $(20 \%)$ a été constaté à leur arrivée aux urgences. Parmi les 41 patients ayant survécu après cette consultation initiale, 12 (29\%) ont été amenés directement au bloc opératoire et 17 (41\%) ont été transférés à l'unité des soins intensifs. Le taux de mortalité global était de $29 \%$.

Conclusion : Les patients victimes de blessures impliquant le métro présentent un taux de mortalité élevé et des blessures graves. La majorité des incidents sont autoinfligés ou liés à l'alcool. Il faudra approfondir la recherche pour identifier les personnes à risque et appliquer des stratégies de prévention optimales afin de réduire le nombre d'incidents.

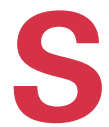

ubway systems have become a staple of rapid transit systems worldwide. As of 2017, there were subway systems in 178 cities in 56 countries, including 18 cities in North America, serving 3 billion passengers annually. ${ }^{1}$ The Toronto Transit Commission (TTC) subway system is Canada's busiest subway system, with a ridership of 416 million in 2018, and ridership has been increasing every year. ${ }^{2}$ Despite yearly improvements to safety, subway injury in Toronto has become an everincreasing problem. Between 2010 and 2016, 148 subway injury incidents were reported, of which 131 were suicide attempts. $^{3}$ A 2018 report noted an average of 23 suicide incidents per year, with a "statistically significant upward trend" since $2013 .{ }^{4}$

Subway-related injuries remain a sparsely studied area of traumatic injury. Studies characterizing injuries have shown that victims commonly experience severe polytrauma. ${ }^{5-8}$ Investigators have also focused on causes of incidents: studies characterizing subway-related fatalities in New York City in 1990-2003 and 2003-2007 showed that suicide attempts accounted for the majority of incidents. $5,6,9$

To our knowledge, the most recent study of death and injury patterns in the TTC subway system was published in $1984 .^{10}$ The authors studied detailed TTC records of all incidents and 119 coroner's reports of subway fatalities between 1954 and 1980. They found similar patterns of head and torso injury as described elsewhere, that incidents were most common between 1000 and 1700 , and that $61 \%$ of those who died had a history of previous psychiatric illness. They recommended the placement of trained inspectors at stations and greater resources put toward mental health.

This aim of the present study was to characterize the potential causes of subway-related trauma and the presentation and outcomes of patients admitted to a level 1 adult trauma centre in Toronto with subway-related injuries. The findings will add to a growing body of literature characterizing subway-related injuries, with the goal of improving management of such patients and possibly recommending prevention strategies.

\section{Methods}

\section{Setting}

There are 4 subway lines currently operational in Toronto. During rush hour, up to 63 trains are on Line 1 simultaneously, 40 trains on Line 2, 6 trains on Line 3, and 4 trains on Line 4. During non-rush-hour periods, there are about 27 trains on Line 1 at any given time. St. Michael's Hospital is 1 of 2 level 1 adult trauma centres in Toronto and is located in the downtown core of the city. The catchment area of St. Michael's Hospital covers the majority of subway stations in Toronto, especially the downtown stations, which average more than 63000 travellers per station per day. ${ }^{2,11}$

\section{Study design, and inclusion and exclusion criteria}

We conducted a retrospective analysis on prospectively collected data in the St. Michael's Hospital Trauma Registry. We identified patients who presented to the emergency department after experiencing a subway-related injury between Jan. 1, 2010, and Dec. 31, 2018, via International Statistical Classification of Diseases and Related Health Problems, 10th Revision E-codes X81, Y02, V050, V051 and W17. We then further screened for descriptions of subway-related injuries. Patients whose injuries did not involve a moving subway train were excluded. The study was approved by the St. Michael's Hospital Research Ethics Board.

\section{Data collection}

Data were abstracted and coded into a password-protected standardized data collection sheet that was stored on internal servers. No patient identifiers were collected. All patients were assigned a unique participant identification number. Data elements abstracted included age, sex, date and time of admission, past medical and psychiatric history, history of alcohol or substance use, vital signs (Glasgow Coma Scale score, systolic blood pressure, respiratory rate) 
on arrival, intent, Injury Severity Score (ISS) (2005 edition), Abbreviated Injury Scale (AIS) scores by body region, blood alcohol concentration, emergency department disposition, postemergency destination, length of stay, days spent in the intensive care unit, days spent receiving mechanical ventilation and discharge disposition. We defined severe injuries as an AIS score of 3 or higher. We defined alcohol intoxication as a blood alcohol concentration greater than $80 \mathrm{mg} / \mathrm{dL}$, as per the legal limit for driving in the Criminal Code of Canada. ${ }^{12}$

\section{Statistical analysis}

We analyzed all data using SAS software v. 9.4 (SAS Institute). We calculated medians and interquartile ranges (IQRs) for continuous variables, and used absolute and relative frequencies to summarize discrete variables.

\section{Results}

During the 9-year study period, 75 people presented to the emergency department after being injured in subway stations. We excluded 24 patients whose injuries were due to falls onto the subway tracks or down stairs in a station without associated injuries secondary to a moving subway train. Our study cohort thus consisted of 51 patients who had been hit by a moving subway train.

The majority of the patients (35 [69\%]) were male. At the time of presentation to the emergency department, 18 patients $(35 \%)$ had a Glasgow Coma Scale score of 8 or less, and $13(25 \%)$ had a systolic blood pressure less than $90 \mathrm{~mm} \mathrm{Hg}$ (Table 1).

Ten patients $(20 \%)$ were declared dead in the emergency department. Of the 41 patients who survived their initial presentation, 12 (29\%) went directly to the operating room, 17 (41\%) were transferred to the intensive care unit, $9(22 \%)$ went to the ward, $1(2 \%)$ was transferred to a secondary acute care hospital, and $2(5 \%)$ were discharged home from the emergency department. The median length of hospital stay was 12 (IQR 0-32) days. The overall mortality rate was $29 \%$; the survival rate for patients who survived their initial presentation was $88 \%(n=36)$.

The number of patients per year ranged from 2 (in 2013) to 12 (in 2014); however, a trend toward an increasing yearly number of patients was apparent during the study period.

\section{Incident characteristics}

The majority of incidents (39 [76\%]) were due to selfharm; (10 [20\%]) were unintentional injuries, and (2 [4\%]) were due to assault. About 1 out of 4 incidents (12 [24\%]) were known to have involved alcohol, with a median blood alcohol concentration of $213.5 \mathrm{mg} / \mathrm{dL}$ (IQR $119-260 \mathrm{mg} / \mathrm{dL}$ ). Ten patients (20\%) were intoxicated, 2 patients (4\%) had a
Table 1. Baseline characteristics of patients who presented to the emergency department after being hit by a moving subway train

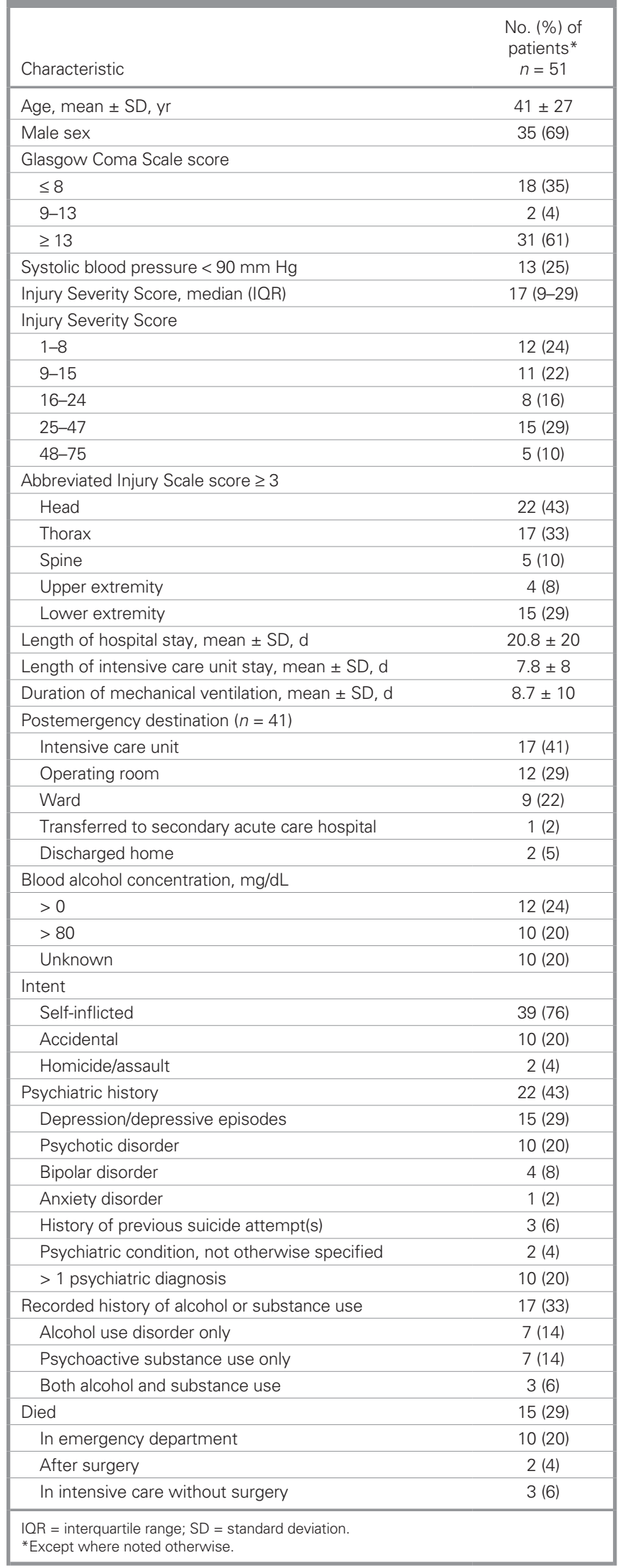


blood alcohol concentration greater than $0 \mathrm{mg} / \mathrm{dL}$ but were not intoxicated, 29 patients (57\%) had a blood alcohol concentration of $0 \mathrm{mg} / \mathrm{dL}$, and in 10 cases (20\%), the blood alcohol concentration was unknown. The presence of alcohol was detected in 8 patients (80\%) with unintentional injuries, of whom 7 were intoxicated. Only 3 patients (8\%) with self-inflicted injuries had been drinking, of whom 2 were intoxicated.

More than half (22 [56\%]) of self-harm injuries were associated with a previous history of psychiatric disorders, and $10(26 \%)$ were associated with a history of alcohol or substance use. The most common diagnoses were a history of depression (15 patients), psychotic disorder (10) and bipolar disorder (4); 10 patients had multiple psychiatric diagnoses (Table 1). None of the 12 patients with unintentional or assault-related injury had a previous history of a psychiatric disorder, although $8(67 \%)$ had a history of alcohol or substance use.

Incidents were distributed equally throughout the year, as divided into quarters (Table 2). Two-thirds of injuries occurred between noon and $1800(20$ [39\%]), or 0600 and noon $(14[27 \%])$. The majority of unintentional injuries $(7 / 10[70 \%])$ happened between 1800 and 0600 , and the majority of self-harm incidents (29/39 [74\%]) occurred between 0600 and 1800 . Incidents were more prevalent on Mondays, Tuesdays and Thursdays; however, there was no association between intent and day of the week.

\section{Injury patterns and characteristics}

The median ISS was 17 (IQR 9-29). Severe injuries were found in the head (22 [43\%]), thorax (17 [33\%]), lower extremities (15 [29\%]), spine (5 [10\%]), upper extremities $(4[8 \%])$ and abdomen $(1[2 \%])$. One in 4 patients $(12$ [24\%]) had an AIS score of 3 or higher in the head and presented to the emergency department with a Glasgow Coma Scale score of 8 or less, which suggested anatomic and physiologic signs of severe head injury. Evaluation of the most common severe injury profiles showed that onethird of patients (17 [33\%]) presented with severe injuries in 1 body region, $19(37 \%)$ had severe injuries in 2 or more body regions, and 15 (29\%) did not have any severe injuries (Table 3). The most common isolated severe injury was in the lower extremity, and the most common combinations of severe injuries were in the head and lower extremity, and head and thorax. The ISS and patterns of injury did not vary based on intent, blood alcohol concentration or psychiatric history.

\section{Discussion}

In the present study, subway-related injuries were associated with high morbidity and mortality, which is in keeping with the findings of Rodier and colleagues. ${ }^{8}$ Also consistent with previous studies, ${ }^{6,8}$ patients most commonly

Table 2. Time characteristics
\begin{tabular}{|lc|} 
& \\
Characteristic & No. $(\%)$ of cases \\
\hline Quarter & $15(29)$ \\
\hline January-March & $11(22)$ \\
\hline April-June & $13(25)$ \\
\hline July-September & $12(24)$ \\
\hline October-December & \\
\hline Day of week & $6(12)$ \\
\hline Sunday & $13(26)$ \\
\hline Monday & $9(18)$ \\
\hline Tuesday & $5(10)$ \\
\hline Wednesday & $11(22)$ \\
\hline Thursday & $3(6)$ \\
\hline Friday & $4(8)$ \\
\hline Saturday & \\
\hline Time of day & $6(12)$ \\
\hline $0600-0959$ & $18(35)$ \\
\hline $1000-1359$ & $10(20)$ \\
\hline $1400-1759$ & $8(16)$ \\
\hline $1800-2159$ & $9(18)$ \\
\hline $2200-0159$ & \\
\hline
\end{tabular}

\begin{tabular}{l} 
Table 3. Patterns of injury \\
\begin{tabular}{|lc|}
\hline Pattern & No. $(\%)$ of patients \\
\hline No severe injuries* & $15(29)$ \\
\hline Severe injury to 1 body region only & $17(33)$ \\
\hline Lower extremity & $7(14)$ \\
\hline Head & $6(12)$ \\
\hline Thorax & $4(8)$ \\
\hline Severe injury to multiple body regions & $19(37)$ \\
\hline Head and lower extremity & $4(8)$ \\
\hline Head and thorax & $4(8)$ \\
\hline Other pattern & $11(22)$ \\
\hline *Defined as Abbreviated Injury Scale score of 3 or higher per body region. \\
\hline
\end{tabular} \\
\hline
\end{tabular}

presented with an isolated severe lower extremity injury, or a combination of severe head and lower extremity, or severe head and thorax injuries. One in 4 patients had a severe head injury, as measured by a combination of anatomic and physiologic variables (head AIS score $\geq 3$ and Glasgow Coma Scale score $\leq 8$ ). This mirrors the results of Johnston and Waddell ${ }^{10}$ for 1954-1980. Of those who survived, $71 \%$ were transported directly from the emergency department to the intensive care unit or the operating room, which further highlights the severity of the injuries.

We found that subway-related injury was about 5 times more lethal and resulted in 4 times the hospital length of stay of the average traumatic injury in the United States. ${ }^{13}$ Our overall mortality rate, $29 \%$, was almost twice the case-fatality rate for severe traumatic injury assessed by emergency medical services in Toronto between 2006 and $2007(16.7 \%),{ }^{14}$ which underscores the high mortality rate among people with subway-related injuries. Our high 
mortality rate is likely to be an underestimate of the overall lethality of these injuries, as we did not capture fatal incidents at the scene in which the person was not transported to hospital. Despite the high overall mortality rate, the survival rate was quite high for patients who survived their initial presentation, at $88 \%$. Primary prevention efforts at the transit system level are required to have an impact on the lethality of these injuries. Anticipation of severe head and extremity injuries among those who survive transport would facilitate planning of receiving teams in hospital.

Subway-related injuries were associated with male sex, self-harm and alcohol use. Our population was similar in age and sex to those in other studies. ${ }^{5,6,8} \mathrm{We}$ found a male predominance $(69 \%)$, although it was less pronounced than in previous studies $(73 \%-86 \% .)^{5,6,8,15}$ Interestingly, this has changed over time: Johnston and Waddell ${ }^{10}$ found a female predominance (58\%) among people with subwayrelated injuries in Toronto in 1954-1980. A 2002 study on rates of suicide and attempted suicide in Canada between 1979 and 1998 showed stable suicide rates with respect to sex. ${ }^{16}$ Further research is necessary to elucidate whether subways became a preferred suicide modality for males at some point in time.

Three of every 4 cases were due to self-harm, which supports the findings of previous studies., ${ }^{5,6}$ Our study also reaffirms findings that unintentional injuries are more commonly associated with alcohol or substance use than a history of a psychiatric disorder. ${ }^{6,8}$ Unintentional injuries were much more commonly associated with alcohol in our study than in other studies $(80 \%$ v. $42 \%-46 \% 5,6)$. Overall alcohol involvement in subway-related injuries varied widely between studies $(25 \%-55 \%) ;{ }^{5,6,8}$ this may reflect differing patterns of alcohol and transit use than in other cities, as well as differences in testing practices in the emergency department.

Subway-related injuries seem to be clustered around specific times and days. Our day of week and time of day distributions were similar to those found previously, corresponding to high stress and ridership at the beginning of the work week and work day, respectively. ${ }^{6,8}$ It is important to note that, in Toronto, the subway does not operate between 0200 and 0600 . Our time distributions were also similar to those found for $1954-1980,{ }^{10}$ which suggests that these patterns have not changed over the previous halfcentury in Toronto. We did not find any seasonal distribution; however, other studies have shown an increased number of incidents during spring and winter. ${ }^{6,8}$ Further research may elucidate whether this clustering of events is due to peaks in ridership or illustrates a temporal relation between self-harm attempts and subway injury.

The prevalence of subways in rapid-transit systems around the world and the severity of subway-related injury necessitate a formal understanding of the mechanisms and causes surrounding subway-related trauma. Until a defini- tive paradigm is introduced to curb additional incidents, further study of subway-related trauma is warranted to inform management and cost-effective prevention strategies. Future studies that evaluate the entirety of the subway system and capture fatal and nonfatal events, focusing on the time, location within the station and speed of the train, might better characterize the relation between injury patterns and outcomes of people with subway-related trauma. In addition, evaluation of suicide attempts that were thwarted by subway personnel or bystanders must be included in order to fully understand the scope of the problem. Characterization of in-hospital complications, discharge destination, and subsequent incidents or followup would help to further guide the care of these patients.

Various primary prevention strategies have been proven to be effective, although they all require substantial financial investment. ${ }^{17}$ Platform screen doors resulted in a reduction of $59.9 \%$ in the subway suicide rate as they were being installed in Hong Kong in 2002,18 and "suicide pits," which increase the distance from the platform to the train, may have contributed to a $21 \%$ reduction in mortality in suicide incidents in London. ${ }^{19}$ A 1987 campaign to reduce inappropriate reporting of suicide in the media in Vienna also resulted in a decrease in subway-related suicide. ${ }^{20}$ Other measures include the placement of trained personnel at high-risk stations during high-risk times, installation of blue lights to reduce suicidal behaviour, and introduction of media campaigns to reduce the portrayal of subways as an attractive means of suicide. ${ }^{17}$

\section{Limitations}

Our study relies on the data collected in the St. Michael's Hospital Trauma Registry, which did not necessarily include data on a full toxicology screen, or information about complications and discharge destination. In addition, we were unable to corroborate our data with TTC reports, which may have provided additional relevant incident information, as well as a better understanding of fatalities at the scene. Last, our study does not fully characterize subway trauma in Toronto, as we did not collect data from other trauma centres in Toronto or the coroner's office.

\section{Conclusion}

Patients with subway-related injuries who presented to a level 1 adult trauma centre in Toronto experienced high mortality rates. They had severe injuries, especially in the head, thorax and lower extremities. The majority of patients were male, three-quarters of incidents were selfharm attempts, and one-quarter were alcohol-related. Further research into the association of outcomes and a history of a psychiatric disorder, early identification of those at risk, and optimal prevention strategies are necessary to curb further incidents. 
Affiliations: From the Schulich School of Medicine and Dentistry, Western University, London, Ont. (Ho); the Li Ka Shing Knowledge Institute, St. Michael's Hospital, Unity Health Toronto, Toronto, Ont. (Ho, Mansour, Gomez); the Department of Surgery A, Galilee Medical Center, Nahariya, Israel (Mansour); the Azrieli Faculty of Medicine of the Galilee, Bar-Ilan University, Safed, Israel (Mansour); the Division of General Surgery, St. Michael's Hospital, Unity Health Toronto, Toronto, Ont. (Gomez); and the Division of General Surgery, Department of Surgery, University of Toronto, Ont. (Gomez).

\section{Competing interests: None declared.}

Contributors: J. Ho and D. Gomez designed the study. J. Ho and D. Gomez acquired the data, which all authors analyzed. J. Ho and D. Gomez wrote the manuscript, which all authors critically revised. All authors gave final approval of the article to be published.

Content licence: This is an Open Access article distributed in accordance with the terms of the Creative Commons Attribution (CC BYNC-ND 4.0) licence, which permits use, distribution and reproduction in any medium, provided that the original publication is properly cited, the use is noncommercial (i.e., research or educational use), and no modifications or adaptations are made. See: https://creativecommons. org/licenses/by-nc-nd/4.0/.

\section{References}

1. Statistics Brief. World metro figures 2018. Brussels: UITP; 2018. Available: https://cms.uitp.org/wp/wp-content/uploads/2020/06/ Statistics-Brief-World-metro-figures-2018V3_WEB.pdf (accessed 2020 Sept. 13).

2. Toronto Transit Commission subway ridership, 2018. Toronto: Toronto Transit Commission. Available: https://transit.toronto.on. ca/spare/0052.shtml (accessed 2019 Nov. 20).

3. Moore O. Death on the tracks: How bad is Toronto transit's suicide problem? Globe and Mail [Toronto]; 2016 Dec. 16. Available: https:// www.theglobeandmail.com/news/toronto/toronto-transit-suicide/ article33347435/ (accessed 2020 Apr. 7).

4. Toronto Transit Commission CEO's report, October 2018. Toronto: Toronto Transit Commission; 2018. Available: https://www.ttc.ca/ PDF/About_the_TTC/CEO_Report/CEO_Report_October_2018_ Update.pdf (accessed 2020 Apr. 7).

5. Gershon RRM, Pearson JM, Nandi V, et al. Epidemiology of subwayrelated fatalities in New York City, 1990-2003. I Safety Res 2008;39: $583-8$.
6. Lin PT, Gill JR. Subway train-related fatalities in New York City: accident versus suicide. 7 Forensic Sci 2009;54:1414-8.

7. Maclean AA, O'Neill AM, Pachter HL, et al. Devastating consequences of subway accidents: traumatic amputations. Am Surg 2006;72:74-6.

8. Rodier SG, DiMaggio CJ, Wall S, et al. Subway-related trauma: an urban public health issue with a high case-fatality rate. 7 Emerg Med 2018;55:165-71.e1.

9. Ratnayake R, Links PS, Eynan R. Suicidal behaviour on subway systems: a review of the epidemiology. 7 Urban Health 2007;84: 766-81.

10. Johnston DW, Waddell JP. Death and injury patterns, Toronto Subway System 1954-1980. 7 Trauma 1984;24:619-22.

11. Bow J. The Scarborough Rapid Transit Line. Toronto: Transit Toronto; 2016. Available: https://transit.toronto.on.ca/subway/5107. shtml (accessed 2019 Jan. 15).

12. Government of Canada. Bill C-46. First Session, Forty-second Parliament, 64-65-66-67 Elizabeth II, 2015-2016-2017-2018; 2018. Available: https://www.parl.ca/DocumentViewer/en/42-1/ bill/C-46/royal-assent\#enH489 (accessed 2019 Sept. 23).

13. DiMaggio C, Ayoung-Chee P, Shinseki M, et al. Traumatic injury in the United States: in-patient epidemiology 2000-2011. Injury 2016; 47:1393-403.

14. Minei JP, Schmicker RH, Kerby JD, et al. Severe traumatic injury. Ann Surg 2010;252:149-57.

15. Erazo N, Baumert J, Ladwig KH. Sex-specific time patterns of suicidal acts on the German railway system. An analysis of 4003 cases. 7 Affect Disord 2004;83:1-9.

16. Langlois S, Morrison P. Suicide deaths and suicide attempts. Health Rep 2002;13:9-22.

17. Barker E, Kolves K, De Leo D. Rail-suicide prevention: systematic literature review of evidence-based activities [Epub ahead of print]. Asia Pac Psychiatry 2017;9. doi: 10.1111/appy.12246.

18. Law CK, Yip PS, Chan WS, et al. Evaluating the effectiveness of barrier installation for preventing railway suicides in Hong Kong. 7 Affect Disord 2009;114:254-62.

19. O'Donnell I, Farmer EDT. The epidemiology of suicide on the London Underground. Soc Sci Med 1994;38:409-18.

20. Etzersdorfer E, Sonneck G. Preventing suicide by influencing massmedia reporting. The Viennese experience 1980-1996. Arch Suicide Res 1998;4:67-74. 